\title{
HUBUNGAN DISMENOREA DENGAN AKTIVITAS BELAJAR MAHASISWI AKADEMI KEBIDANAN DELIMA PERSADA GRESIK 2018
}

\author{
The Corelation Between Dysmenorrhea and Learning Activities Female Students of Midwifery \\ Delima Persada Gresik 2018 \\ Diyana Faricha Hanum \\ Program Studi DIII Kebidanan, Akademi Kebidanan Delima Persada Gresik, Gresik 61111
}

\section{ABSTRACT}

The purpose of this study was to analyze the relationship between dysmenorrhea and the learning activities of Delima Persada Gresik midwifery students. This study used observational analytic with the Chi-Square approach. The subject of this study was a student of Delima Persada Gresik midwifery academy by using a Random Sampling technique. Data collection techniques using questionnaires and analyzed using bivariate analysis. From the results of the analysis showed that if Asymp. Sig. (2-sided) $<0.05$ so there is a relationship between dysmenorrhoea and learning activities. The knowledge and handling dysmenorrheal in correct way are needed by the students to solve the dysmenorrhea problem, so it won't distrub their learning and daily activity and they can achieve their best performance.

Keywords : dysmenorrhea, learning activities

\section{ABSTRAK}

Tujuan penelitian ini untuk menganalisis hubungan antara disminorea dengan aktivitas belajar mahasiswi akademi kebidanan Delima Persada Gresik. Penelitian ini menggunakan analitik observasional dengan pendekatan Chi-Square. Subjek penelitian ini adalah mahasiswi akademi kebidanan Delima Persada Gresik dengan teknik Random Sampling. Teknik pengumpulan data menggunakan kuesioner dan dianalisis menggunakan Analisis bivariat. Dari hasil analisis menunjukkan bahwa jika Asymp.Sig. (2-sided) $<0,05$ maka ada hubungan antara dismenorea dengan aktivitas belajar. Pengetahuan dan penanganan masalah dismenore yang tepat diperlukan oleh mahasiswa, agar tidak mengganggu aktivitas belajar bahkan aktivitas sehari-hari sehingga nilai prestasi dalam belajar terus meningkat.

Kata Kunci : dismenore, aktivitas belajar

\section{PENDAHULUAN}

Masa remaja adalah masa peralihan dari masa anak ke masa dewasa yakni antara usia 12 sampai dengan 21 tahun, mengingat dari pengertian tersebut maka sulit untuk menentukan batas umurnya. Masa remaja dimulai pada saat timbulnya perubahan yang berkaitan dengan tanda-tanda perubahan fisik, masa ini disebut juga masa pubertas atau adolescence (Gunarsa, 2008). Dan menstruasi merupakan salah satu perubahan fisologis pada remaja wanita. Ketika menstruasi terjadi pada tiap wanita akan memiliki pengalaman yang berbeda-beda. Ada beebrapa perempuan yang mengalami haid tanpa masalah, tetapi tidak sedikit dari mereka yang mengalami haid disertai dengan keluhan nyeri perut bagian bawah. Rasa nyeri ini disebut dismenorea, rasa nyeri yang ditimbulkan saat menstruasi ini membuat wanita merasa tidak nyaman sehingga akan mempengaruhi aktivitas sehari-hari.

Dismenorhea adalah salah satu gangguan pada masa menstruasi, gangguan ini berasal dari kram uterus dan terjadi selama menstruasi, nyeri dapat timbul akibat kontraksi disritmik miometrium dengan satu gejala tau lebih mulai dari nyeri ringan sampai berat di perut bagian bawah, bokong dan nyeri spasmodic di sisi medial paha (Runjati, dkk. 2017).

Perempuan di setiap Negara mengalami nyeri menstruasi rata-rata lebih 
Hubungan Dismenorea dengan Aktivitas Belajar Mahasiswi Akademi Kebidanan Delima Persada Gresik 2018

dari 50\%. Di Amerika didapatkan prosentase angka kejadian nyeri haid sekitar $60 \%$, di Swedia sekitar $72 \%$. Sedangkan sekitar 55\% terjadi nyeri menstruasi di Indonesia. Dari hasil penelitian yang ada, di Indonesia ditemukan angka kejadian dysmenorrhea sebesar $64.25 \%$ yang terdiri dari $54,89 \%$ dysmenorrhea primer dan 9,36 \% untuk dysmenorrhea sekunder. Nyeri haid atau dismenorea memiliki dampak pada remaja putri, salah satui dampaknya adalah terganggunya aktivitas sehari-hari.

Remaja yang mengalami nyeri pada saat menstruasi membatasi aktivitas harian mereka khususnya aktivitas belajar di sekolah maupun kampus. Seorang pelajar perempuan mengalami nyeri haid, aktivitas proses belajar mereka di sekolah terganggu dan tidak jarang hal tersebut membuat mereka tidak hadir di sekolah. Selain itu, kualitas hidup cenderung berkurang, misalnya seorang pelajar wanita yang mengalami nyeri haid tidak bisa berkonsentrasi belajar sehingga motivasi belajar mereka berkurang karena nyeri haid/dismenorea yang dirasakan pada saat proses belajar mengajar (Ningsih, 2011).

Data dari Badan Pusat Statistik (BPS) Provinsi Jawa Timur (2010) menunjukan total dari remaja wanita yang reproduksi yaitu berumur 10-24 tahun adalah sebesar 56.598 jiwa. Sedangkan untuk yang mengalami dismenorea dan berkunjug di poli kebidanan sebesar 11565 jiwa (1,31\%). Dismenore dapat memepengaruhi lebih dari separuh wanita yang sedang menstruasi, dan prevalensi yang dilaporkan sangat bervariasi. Puncak nyeri haid/dismenore primer terjadi pada akhir masa remaja dan di awal usia 20-an. insiden disminore pada remaja putri dilaporkan sekitar 92\%. Insiden ini mulai berkurang bersamaan dengan bertambahnya usia (Setiawan, dan Lestari, 2017).

Tujuan penelitian ini untuk menganalisis hubungan antara disminorea dengan aktivitas belajar mahasiswi akademi kebidanan delima persada Gresik

\section{METODE PENELITIAN}

Penelitian ini menggunakan desain analitik observasional dengan analisis bivariat. Analisis data menggunakan uji ChiSquare. Lokasi penelitian di akademi kebidanan Delima Persada Gresik Pada bulan November 2018 dengan jumlah sampel 60 mahasiswi, dengan teknik Simple Random Sampling. Teknik pengumpulan data menggunakan kuesioner.

\section{HASIL DAN PEMBAHASAN}

\section{Karateristik Responden}

Karakteristik subyek penelitian menunjukkan bahwa dari 60 mahasiswi yang diteliti yaitu sebanyak 51 orang $(86,7 \%)$ mengalami haid pertama kali/menarche di usia $10-15$ Tahun. Sebanyak 46 orang $(76,7 \%)$ dengan lama haid 3-7 Hari. Dan sebanyak 48 orang $(80 \%)$ mengalami gangguan haid (Dismenore) ada pada table 1.

Tabel 1 Distribusi Frekuensi karateristik mahasiswi Akademi Kebidanan Delima Persada Gresik

\begin{tabular}{lcc}
\hline Karateristik & F & \% \\
\hline Usia Menarche & & \\
10.15 Tahun & 51 & 86,7 \\
> 15 Tahun & 9 & 13,3 \\
\hline Lama Haid & & \\
3-7 Hari & 46 & 76,7 \\
>7 Hari & 14 & 23,3 \\
\hline Dismenore & & \\
Dismenore & 48 & 80 \\
Tidak Dismenore & 12 & 20 \\
\hline Total & 60 & 100 \\
\hline
\end{tabular}

\section{Hubungan Antara Dismenorea Dengan} Aktivitas Belajar

Dismenorea adalah salah satu gangguan menstruasi, yaitu rasa nyeri perut bagian bawah yang timbul saat menstruasi, nyeri yang ditimbulkan dapat mengganggu aktivitas sehari-hari.

Dari hasil analisis spss menunjukkan bahwa jika Asymp.Sig. (2-sided) $<0,05$ maka ada hubungan antara Dismenorea Dengan Aktivitas Belajar (Tabel 2).

Tabel 2 Hubungan Dismenore Dengan Aktivitas Belajar 
Hubungan Dismenorea dengan Aktivitas Belajar Mahasiswi Akademi Kebidanan Delima Persada Gresik 2018

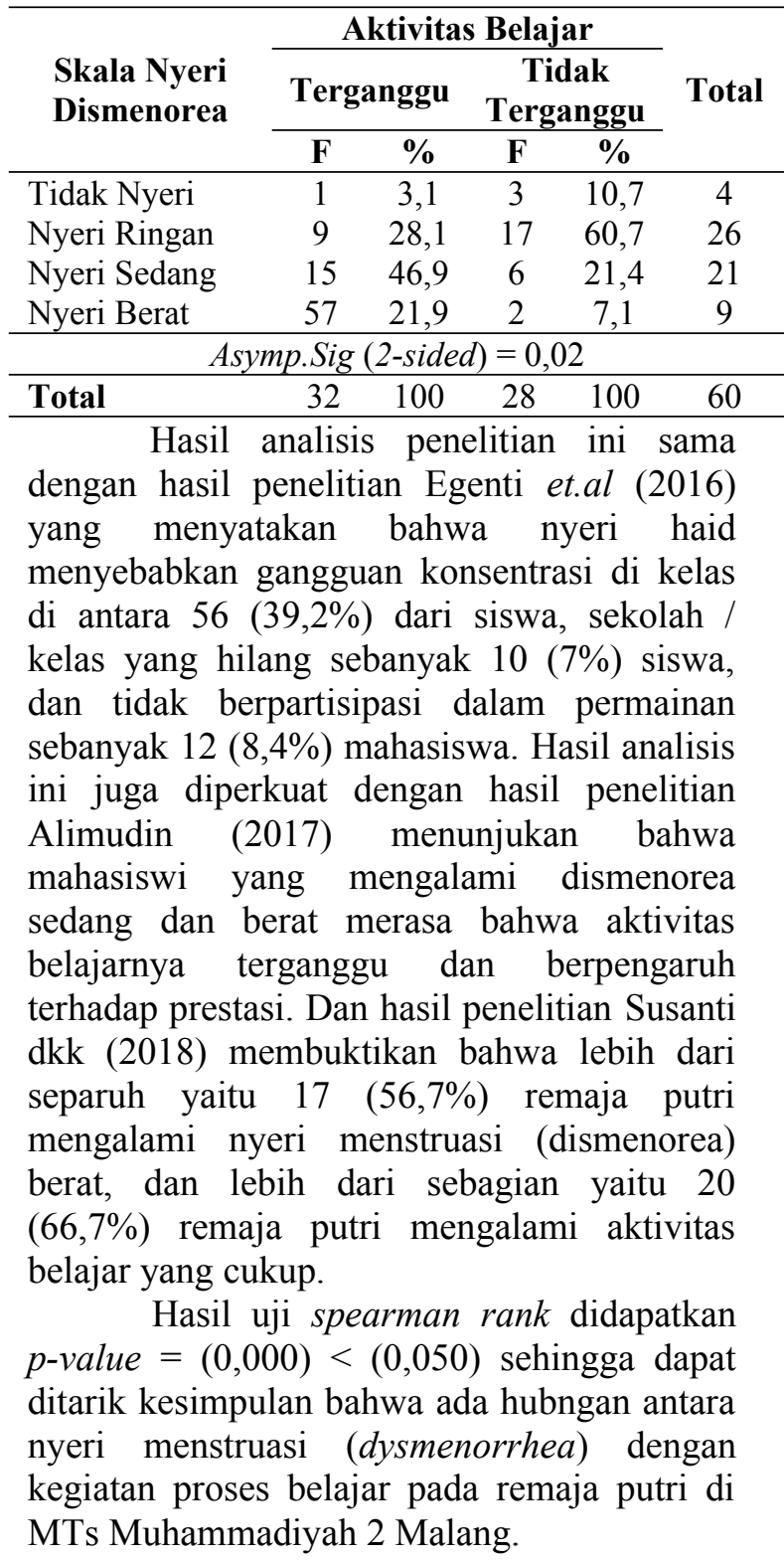

\section{KESIMPULAN}

Hasil penelitian ini membuktikan bahwa ada hubungan antara dismenore dengan aktivitas belajar. Namun masih perlu diteliti ulang tentang hubungan nyeri menstruasi dengan kegiatan proses belajar yang terganggu atau tidak terganggu.

Mahasiswa perlu mengetahui dan bisa menangani masalah dismenore dengan tepat sehingga tidak akan mempengaruhi dari aktivitas belajar bahkan aktivitas sehari-hari. Dismenore bisa teratasi dengan melakukan peregangan/streitching, endorphine massage bahkan bisa dengan mengkonsumsi obat penghilang rasa nyeri.

\section{DAFTAR PUSTAKA}

Alimudin, A. 2017. Hubungan Dismenorea dengan aktivitas belajar mahasiswa prodi DIV Jurusan kebidanan POLTEKES KEMENKES Kendari. Skripsi Kendari: Kementrian Kesehatan Republik Indonesia Poloteknik Kesehatan Kendari Jurusan Kebidanan. Diakses Pada 8 November 2018

Egenti. N.B, Onuorah. U.C, Ebenebe. U.E, et.al. 2016. Perception of Dysmenorrhea and Its Relationship to School Activities among Senior Secondary School Students in Nnewi, Nigeria. Sciendomain. 4(2): 1-8

Gunarsa, Singgih, D. Gunarsah, Yulia S,D. 2008. Psikologi Perkembangan anak dan remaja. Jakarta: Gunung Mulia

Ningsih, R. 2011. Efektifitas Paket Pereda Intensitas Nyeri Pada Remaja Dengan Disminore di SMAN Kecamatan Curup. http://lontar.ui.ac.id. Diakses pada tanggal 10 November 2018

Runjati, Umar.S, dan Ester.M. 2017. Kebidanan Teori dan Asuhan Volume 2. Jakarta: EGC

Setiawan, S.A. dan Lestari, L. 2017. Hubungan Nyeri Haid (Dismenore) dengan Aktivitas Belajar Sehari-Hari Pada Remaja Putri Kelas VII Di SMPN 3 Pulung. Jurnal Delima Harapan Volume 9 No.8

Susanti, R.D. Utami, N.W. dan Lasri. 2018. Hubungan Nyeri Haid (Dysmenorrhea) Dengan Aktivitas Belajar Pada Remaja Putri MTs Muhammadiyah 2. Nursing New. Volume 3 No.1 